\title{
Proceeding
}

Supplementary Issue: Autumn Conferences of Sports Science. Costa Blanca Sports Science Events, 18-19 December 2020. Alicante, Spain.

\section{Effects of two different small-sided games protocols on physiological parameters of professional soccer players}

IOANNIS ISPIRLIDIS

Department of Physical Education and Sport Science, Democritus University of Thrace, Komotini, Greece

\begin{abstract}
The aim of the present study was to evaluate the effect of two different small-sided game protocols on the internal and external training parameters of professional soccer players. Twenty-two $(\mathrm{N}=22) \mathrm{Greek}$ Superleague 2 team players (age: $28.69 \pm 3.4 \mathrm{yr}$.; stature: $179.0 \pm 25 \mathrm{~cm}$; body mass: $76.0 \pm 5.6 \mathrm{~kg}$; body fat: $7.68 \pm 1.5 \%$ ) participated in this study. The small-sided games (SSGs) included two research protocols+: A) $6+6$ vs $6+6+2 \mathrm{GK}\left(45 \times 40 \mathrm{~m} ; 150 \mathrm{~m}^{2}\right.$ per player) with a duration of $4 \times 4$ min and B) 10 vs $10+2 \mathrm{GK}(75 \times 65 \mathrm{~m}$; $244 \mathrm{~m}^{2}$ per player) with a duration of $4 \times 8 \mathrm{~min}$. The heart rate of the players, the covered distances, the amount of sprints and the number of accelerations/decelerations were recorded during the above protocols via shortrange radio telemetry (Polar Team Sports System). The $t$-test (paired samples) was used to compare the differences between the two SSGs protocols. The results showed that the $6+6$ vs $6+6+2$ GK SSGs induced significantly higher heart rate in relation to the 10 vs $10+2$ GK SSGs $(p<.05)$. Furthermore, during the 10 vs $10+2 G K$ SSGs the players covered more distances with high speed, while during the $6+6$ vs $6+6+2 G K$ SSGs a great number of accelerations and decelerations were recorded. Summarizing, the studied SSGs protocols resulted in different physical adaptations regarding the intensity, endurance and strength of the professional players. Thus, the trainers should carefully select the appropriate program focusing on the orientation of their training and the expected results.
\end{abstract}

Keywords: SSGs; Pitch dimensions; Training load; Performance.

\section{Cite this article as:}

Ispirlidis, I. (2021). Effects of two different small-sided games protocols on physiological parameters of professional soccer players. Journal of Human Sport and Exercise, 16(2proc), S164-S171. doi:https://doi.org/10.14198/jhse.2021.16.Proc2.01

Corresponding author. Department of Physical Education and Sport Science, Democritus University of Thrace, Komotini, Greece.

E-mail: iispyrli@phyed.duth.gr

Abstract submitted to: Autumn Conferences of Sports Science. Costa Blanca Sports Science Events, 18-19 December 2020. Alicante, Spain.

JOURNAL OF HUMAN SPORT \& EXERCISE ISSN 1988-5202

(c) Faculty of Education. University of Alicante

doi:10.14198/jhse.2021.16.Proc2.01 


\section{INTRODUCTION}

The small-sided games (SSGs) is a training method in soccer with few players in smaller pitches and different playing rules than a typical game (Hill-Haas et al., 2008). The SSGs are considered an effective training method that improves team and individual performance of the soccer players (Ford, Yates \& Williams, 2010). The small-sided games are commonly adopted as a training method because of their similarity with the intensities of the match (Aguiar et al., 2012). The effectiveness on technical and tactical aspects, (Clemente et al., 2014; Sanchez-Sanchez et al., 2017) the enhancement of physiological and physical variables (Bekris, Gioldasis \& Gissis, 2014; Casamichana \& Castellano, 2015; Faude et al., 2014), the examination of players' kinematic characteristics (Gaudino, Alberti \& laia, 2014; Mallo \& Navarro, 2008) and the improvement of motor learning parameters simulate the match (Gonçalves et al., 2016; Smeeton, Ward \& Williams, 2004). Furthermore, the aforementioned parameters could simultaneously developed by increasing the players' strength, speed and endurance (Owen, 2011).

Furthermore, the small-sided games have a significant effect on physiological, technical and tactical aspects by manipulating game constraints such as pitch dimension, number of players, and game rules. Consequently, different SSGs formats result in different heart rate responses (HR), the percentage of maximal heart rate $\left(\% \mathrm{HR}_{\max }\right)$ and blood lactate (BLa) accumulation (Hill-Haas et al., 2011; Impellizzeri et al., 2011; Rampinini et al., 2007). The SSGs formats with fewer players (2vs2 \& 3vs3) that maintain duration, pitch size, rules of the game resulted in the players greater $H R, H R_{\max }$ and $B_{L a}$ than formats with higher number of players (Aguiar et al., 2013; Hill-Haas et al., 2009). Similarly, the SSGs formats in larger pitches demand more intensive action than formats in smaller pitches (Casamichana \& Castellano, 2010; Hodgson, Akenhead \& Thomas, 2014). Regarding the physical parameters, the SSGs formats played on medium and large areas demand greater covered distance, sprints and accelerations/decelerations (Ade, Harley \& Bradley, 2014). Furthermore, it has been suggested that the SSGs formats with different rules affect physiological adaptations. In particular, SSGs protocols, by stopping the ball on the line to score, demand greater HR and BLa than shot goals to score while the SSGs format with one touch rule showed a higher average HR (Halouani et al., 2017).

It is clear that several studies have used the SSGs in order to evaluate their effects on players' performance. However, the lack of consistency in the designing of the games, the samples age variation among studies and the playing rules among the SSGs make the comparison difficult. Moreover, although training staff is responsible for a great number of players that should work together team-tactics, the majority of the studies assess the effects of the SSGs with few players (2vs2 to 6vs6) on physiological, physical and technicaltactical adaptations in the game (Köklü et al., 2017; Sanchez-Sanchez et al., 2018). Different SSGs formats may show different responses and therefore they may be used for a different purpose as part of soccer training. In addition, amateur soccer players participated in the majority of the studies while the professional players adopt a different way of approaching SSGs formats remains unclear. The main hypothesis was that the SSGs with fewer players would result in higher HR values and increased external parameters compared to the SSGs with greater number of players. Thus, the aim of the present study was to examine the effect of different SSG formats on internal (HR) and external (sprints, accelerations/decelerations) training parameters of professional soccer players. 


\section{MATERIALS AND METHODS}

\section{Subjects}

Twenty-two ( $N=22$ ) professional soccer players (age: $28.7 \pm 3.4$ yrs.; stature: $179 \pm 25 \mathrm{~cm}$; body mass: $76.0 \pm 5.6 \mathrm{~kg}$; body fat: $7.68 \pm 1.5 \%$ ) participated in the current study. Their normal training program during the competitive period involved four training sessions per week in addition to one official game. All the players were notified about research design and its requirements along with the potential benefits and risks and the amount of the players provided written consent that was based on the Declaration of Helsinki. The Ethics Committee of the Democritus University of Thrace gave its institutional approval for the study.

\section{Experimental procedure}

The amount of the studied players participated in two training sessions in counterbalance order. In the first session, Group A complete a 20 min standard warm-up, followed by $8 \times 4 \mathrm{~min}$ SSGs played with $6+6$ vs $6+6$ players, two goalkeepers with free touches in a $45 \times 40 \mathrm{~m}$ pitch (Figure 1). In the second session, Group B complete a $20 \mathrm{~min}$ standard warm-up, followed by $4 \times 8 \mathrm{~min}$ SSGs played with $10 \mathrm{vs} 10$ players, two goalkeepers with free touches in a $75 \times 65 \mathrm{~m}$ pitch. The SSGs ratio per player (field dimension divided by the number of players) was $150 \mathrm{~m}^{2}$ and $244 \mathrm{~m}^{2}$ for Group A and Group B and illustrated in Figure 1.
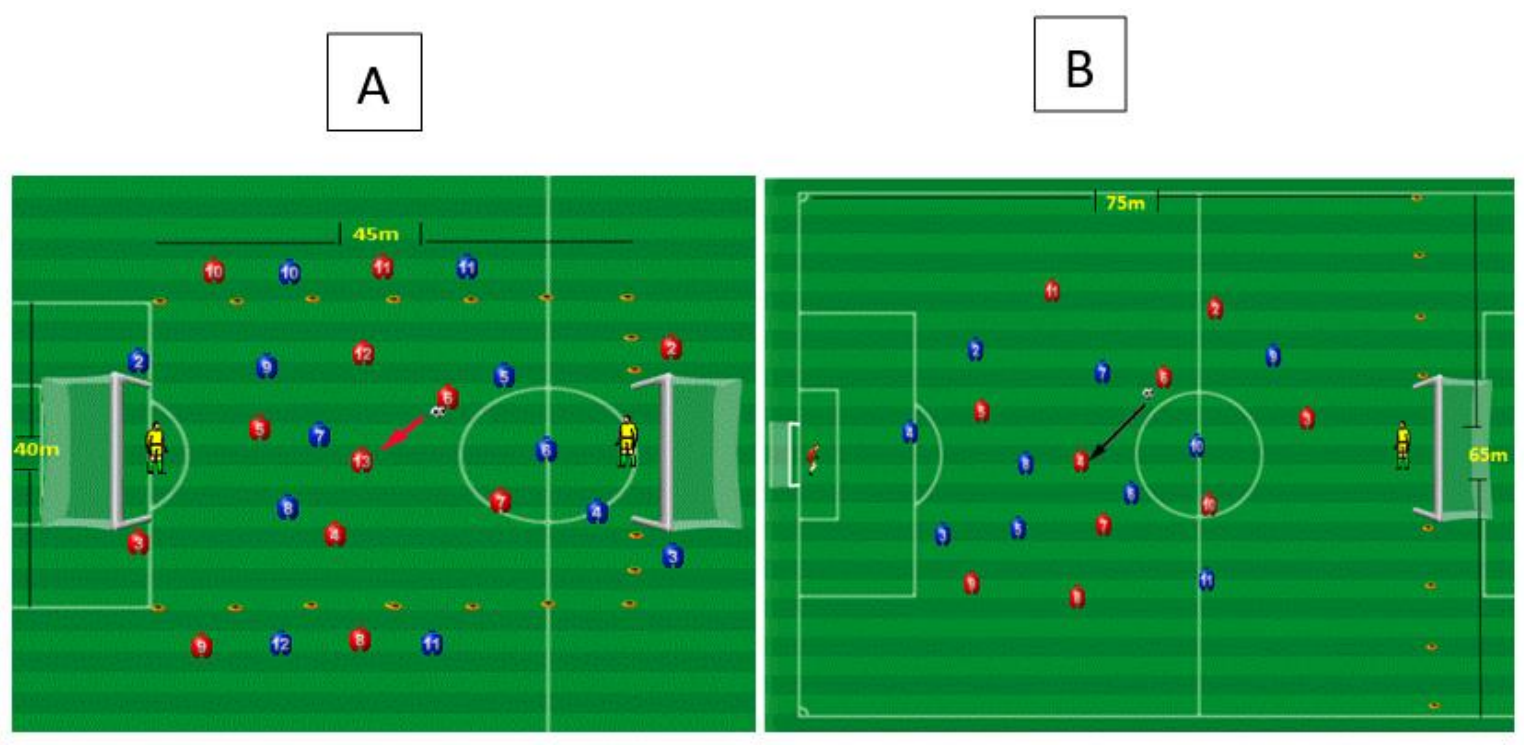

Figure 1. Small-Sided Game Formats. A represents 10vs10+2GK (75X65 m; $2.44 \mathrm{~m}^{2}$ per player) format and $B$ represents $6+6 v s 6+6+2 G K\left(45 X 40 \mathrm{~m} ; 150 \mathrm{~m}^{2}\right.$ per player) format.

The heart rate monitoring of each player was recorded at $5 \mathrm{~Hz}$ during the SSGs via short-range radio telemetry (Polar Team Sports System; Polar Electro Oy, Kempele, Finland). Exercise intensity was assessed using the participants' $H R$, expressed as a percentage of their maximum heart rate $\left(\% H R_{\max }\right)$ and classified into three zones: a) zone 1 (84-89), b) zone 2 (90-94), c) zone 3 (95-100). For the data analysis, four training intensity zones were selected: a) zone $1\left(8-14.39 \mathrm{~km}^{\mathrm{h}} \mathrm{h}^{-1}\right)$, b) zone $2\left(14.4-19.79 \mathrm{~km} \cdot \mathrm{h}^{-1}\right)$, c) zone $3\left(19.8-24.99 \mathrm{~km} \cdot \mathrm{h}^{-1}\right)$, d) zone $4\left(>25 \mathrm{~km} \cdot \mathrm{h}^{-1}\right)$. GPS system further assessed the total number of sprints $\left(>25 \mathrm{~km} \cdot \mathrm{h}^{-1}\right)$ and the amount of high $\left(>3 \mathrm{~m} / \mathrm{sec}^{2}\right)$ and medium $\left(2-3 \mathrm{~m} / \mathrm{sec}^{2}\right)$ accelerations and high $\left(>-3 \mathrm{~m} / \mathrm{sec}^{2}\right)$ and medium $\left(-2\right.$ to $\left.-3 \mathrm{~m} / \mathrm{sec}^{2}\right)$ decelerations. 


\section{Statistical analysis}

The normal distribution of the data was verified by using the Shapiro-Wilk test. In addition, the scatterplots were used in order to determine whether a linear model is reasonable for the variables of the players' performance. Paired samples t-tests were used to compare the differences between the two different game formats. The criterion level for significance was set at $p<.05$. Statistical analysis was performed in SPSS version 20.0 (SPSS, Inc., Chicago, IL).

\section{RESULTS}

Table 1. Physiological parameters between the two different SSGs formats $( \pm S D)$.

\begin{tabular}{|c|c|c|c|}
\hline SSG formats & Group A 6+6vs6+6+2GK & Group B 10vs10+2GK & t-test \\
\hline Time at $84-89 \% \mathrm{HR}_{\max }$ & $6.98(2.13)$ & $10.51(2.69)$ & $1.46^{* * *}$ \\
\hline Time at $90-94 \% \mathrm{HR}_{\max }$ & $8.70(3.04)$ & $5.05(2.98)$ & $-1.21^{* * *}$ \\
\hline Time at $95-100 \% \mathrm{HR}_{\max }$ & $2.29(2.84)$ & $0.64(1.00)$ & $-0.86^{* * *}$ \\
\hline Zone 1 (8-14.39Km/h-1) & $1419.81(200.40)$ & $1648.96(264.34)$ & $0.99^{* * *}$ \\
\hline Zone $2\left(14.4-19.79 \mathrm{Km} / \mathrm{h}^{-1}\right)$ & $536.29(95.46)$ & $534.68(139.56)$ & -0.01 \\
\hline Zone $3\left(19.8-24.99 \mathrm{Km} / \mathrm{h}^{-1}\right)$ & $125.03(45.59)$ & $152.87(64.96)$ & $0.50^{*}$ \\
\hline Zone $4\left(>25 \mathrm{Km} / \mathrm{h}^{-1}\right)$ & $8.16(6.37)$ & $34.57(31.49)$ & $1.40^{* * *}$ \\
\hline Sprint number $\left(>25 \mathrm{Km} / \mathrm{h}^{-1}\right)$ & $1.43(0.88)$ & $3.40(2.28)$ & $1.25^{\star * *}$ \\
\hline Acceleration $>3 \mathrm{~m} / \mathrm{sec}^{2}$ & $11.11(2.72)$ & $8.68(2.81)$ & $-0.88^{* * *}$ \\
\hline Acceleration 2-3 m/sec ${ }^{2}$ & 55.09 (3.78) & $41.81(7.31)$ & $-2.39^{\star * *}$ \\
\hline Deceleration $>-3 \mathrm{~m} / \mathrm{sec}^{2}$ & $12.29(3.08)$ & $11.51(3.90)$ & -0.22 \\
\hline Deceleration $-2-3 \mathrm{~m} / \mathrm{sec}^{2}$ & $44.88(6.11)$ & $39.96(5.62)$ & $-0.84^{* *}$ \\
\hline
\end{tabular}

The results showed significant differences between the SSGs protocols on the players' HR zones (Table 1). More specific, the players' time-spend playing at HR zone 1 was significantly increased for Group B compared to Group A (10.51 \pm 2.69 b. min $^{-1}$ vs $6.98 \pm 2.13$ b. min $\left.^{-1} ; p<.05\right)$. In contrast, the players' time spent playing at HR zone 2 and HR zone 3 was significantly increased for Group A compared to Group B (8.70 \pm 3.04 b. inin $^{-1}$ vs $5.05 \pm 2.98$ b. min-1 $^{-1}$ for zone 2 and $2.29 \pm 2.84$ b. min $^{-1}$ vs $0.64 \pm 1$ b. min $^{-1}$ for zone 3 ( $\left.<<.05\right)$.

Furthermore, significant differences were observed between the SSGs protocols for the intensity zones (Table 1). More specific, the distance covered $(\mathrm{m})$ by the players' were significantly greater for Group B in relation to the Group A for the zone 1 (1648.96 $\pm 264.34 \mathrm{~m}$ vs $1419.81 \pm 200.40 \mathrm{~m}$ ) for the zone $3(152.87$ $\pm 64.96 \mathrm{~m}$ vs $125.03 \pm 45.59 \mathrm{~m}$ ) and for the zone 4 [34.57 $\pm 31.49 \mathrm{~m}$ vs $8.16 \pm 6.37 \mathrm{~m}$ ], $(p<.05)$. In contrast, the distance covered by the players in the intensity zone 2 showed with non-significant differences between group A and Group B [536.29 $\pm 95.49 \mathrm{~m}$ vs $534.68 \pm 139.56 \mathrm{~m}],(p=.62)$.

Finally, significant differences were recorded between the SSGs protocols in the participants' sprints, accelerations and decelerations (Table 1). Specifically, the players of the Group B performed with significant greater amount of sprints in relation to the players of Group A [3.40 \pm 2.28 vs $1.43 \pm 0.88],(p<.05)$. In contrast, players of Group A performed with significantly greater number of medium and high accelerations and medium decelerations compared to players of Group B $(p<.05)$. No-significant differences between groups were found for high decelerations $\left(12.29 \pm 3.08 \mathrm{~m} / \mathrm{sec}^{2}\right.$ vs $\left.11.51 \pm 3.9 \mathrm{~m} / \mathrm{sec}^{2}\right)$ for group A and Group $B$ respectively $(p<.05)$. 


\section{DISCUSSION}

The main findings of the present study were that SSGs formats with fewer players ( $6+6$ vs $6+6+2 G K$ ) resulted a higher playing HR values while SSGs formats with more players (10 vs $10+2 G K$ ) resulted an increase in external parameters on the players performance. Based on these findings the main hypothesis of the study is partly accepted. The results of the present study showed increased HR values for SSGs with fewer players compared to SSGs with more players. Specifically, the players who participated in $6+6$ vs $6+6$ SSGs spent longer time in intensities from 90 to $94 \%$ and 95 to $100 \%$ of $\mathrm{HR}_{\max }$ compared to the players of $10 \mathrm{vs} 10 \mathrm{SSGs}$ who showed increased values in intensities from 84 to $89 \%$ of $H R_{\max }$. Similar results were reported by Owen et al. (2011) who confirmed that 3vs3+GKs SSGs induced higher HR responses in the players compared to 9vs9+GKs SSGs. Little and Williams, 2007 reported that the training intensity differentiate according to pitch dimensions confirmed that the shorter the personal playing space the greater the physiological adaptation. This finding may explain the HR differences because of different personal space between $6+6$ vs $6+6$ SSGs (150m2/player) and 10 vs $10 \mathrm{SSGs}(244 \mathrm{~m} 2 /$ player) of the present study. Furthermore, it seems that the present study professional players have similar HR responses with amateur players reported in previous studies. In addition, Bujalance-Moreno, Latorre-Roman and Garcia-Pinillos, (2019) reported that the players obtain higher \%HR when played in a smaller format compared to larger formats. Therefore, it seems that pitch dimension had a significant role in HR responses with the coaches should manipulate pitch dimensions in order to succeed greater cardiovascular adaptations of their players.

Additionally, the results of the present study showed significant differences on the players intensity used for the distance covering (Table 1). In particular, 10 vs 10 SSGs protocol covered significantly greater distances in intensities between $8-14.3925 \mathrm{~km} . \mathrm{h}^{-1}$ and $19.8-24.9925 \mathrm{~km} . \mathrm{h}^{-1}$ compared to $6 \times 6$ vs $6 \times 6$ SSGs training protocol. These findings are in accordance with previous studies which found greater covered distances in high speeds when large pitch dimension SSGs were used (Casamichana, Bradley \& Castellano, 2019; Rebelo et al., 2016). A larger pitch seems that permits soccer player to develop higher playing intensities for games such as passing the ball to the empty space, sprinting for catching the ball, sprinting for defending and/or offensive parameters. In contrast, a smaller pitch seems to be more appropriate for technical issues, such as dribbling or short passing and according to the aim of each one training session coaches could use larger or smaller pitches.

Moreover, in the present study a significant differentiation on the amount of sprints (above $25 \mathrm{~km} . \mathrm{h}^{-1}$ ) between the two protocols was observed (Table 1). The 10 vs 10 SSGs protocol performed more sprints compared to $6+6$ vs $6+6$ SSG protocol. Relevant studies found that the total number of sprints was higher in the SSGs played on medium and large pitches compared to small pitches (Bujalance-Moreno, Latorre-Román \& García-Pinillos, 2019). In addition, Casamichana and Castellano (2010) concluded that during the 8vs8 SSGs in larger area players covered greater distances with high speed $\left(>15 \mathrm{~km} \cdot \mathrm{h}^{-1}\right)$ and sprint $\left(>25 \mathrm{~km} \cdot \mathrm{h}^{-1}\right)$ compared to $6 \mathrm{vs} 6$ and 3vs3 SSGs in smaller area. Although modern soccer requires the soccer players to be able to perform in small and limited spaces, several goal scoring opportunities are observed after a maximum sprint of the player in the empty space of the field. It is important, therefore, for coaches to select appropriate SSGs formats that would permit players to develop their maximum playing speed.

Additionally, the total number of accelerations and decelerations significantly differed between groups (Table 1). Group $A$ showed an increased number of high and medium accelerations and medium decelerations compared to Group B, whereas there were no significant differences in high decelerations between the two groups. Similar results were reported in previous studies which found that during the SSGs with fewer players (5vs5 \& 7vs7) participants performed more medium accelerations and decelerations compared to SSGs with 
increased number (10vs10) of players (Gaudino, Alberti \& laia, 2014; Aasgaard \& Kilding, 2020). Similar with the above findings, Rebelo et al., (2016) presented that the players performed a greater number of high and medium accelerations as well as medium decelerations during the 4vs4 SSGs in relation to the 8vs8 SSGs. A factor that possibly affects acceleration and deceleration rates is ball contact. The smaller number of players the more ball contacts from all players (Capranica et al., 2001). Recently, Gimenez et al. (2018) showed that when participants played with one touch they perform with their highest intensity (acceleration of $>4 \mathrm{~m} / \mathrm{s} 2$ ). If this is the case, then the SSGs format with fewer players is expected to lead to the players to perform with more accelerations and decelerations and coaches could take the benefit from this finding in the design of the training program of their players.

\section{CONCLUSIONS}

The current study showed that $6+6$ vs $6+6+2$ GK SSGs caused significantly greater HR responses in $90-94 \%$ and $95-100 \%$ of $\mathrm{HR}_{\max }$ compared to 10 vs $10+2$ GK SSGs in which a longer time was recorded in $84-89 \%$ range. Furthermore, the SSGs with larger area increased the distances the players covered with high speeds but the SSGs with smaller area showed greater number of accelerations and decelerations. It is clear that both formats of the SSGs achieve different physical fitness adaptations in speed, endurance and strength. Soccer trainers should carefully select the appropriate training program according to the aim of the training and the expected results. Future studies could assess parameters such as muscle lesions because of the small-sided games effects in order to apply this training method into the microcycle sessions with a low risk of injuries and/or muscle damages.

\section{REFERENCES}

Aasgaard, M. \& Kilding, A.E. (2020). Does man marking influence running outputs and intensity during small-sided soccer games? Journal of Strength and Conditioning Research, 4(11), 3266-3274. https://doi.org/10.1519/JSC.0000000000002668

Ade, J.D., Harley, J.A. \& Bradley, P.S. (2014). Physiological response, time-motion characteristics, and reproducibility of various speed-endurance drills in elite youth soccer players: Small-sided games versus generic running. International Journal in Sports Physiology and Performance, 9(3), 471-479. https://doi.org/10.1123/ijspp.2013-0390

Aguiar, M., Botelho, G., Lago, C., Maças, V. \& Sampaio, J. (2012). A review on the effects of soccer small-sided games. Journal in Human Kinetics, 33,103-113. https://doi.org/10.2478/v10078-0120049-x

Aguiar, M.V., Botelho, G.M., Gonçalves, B.S. \& Sampaio, J.E. (2013). Physiological responses and activity profiles of football small-sided games. Journal in Strength and Conditioning Research, 27(5), 1287-1294. https://doi.org/10.1519/JSC.0b013e318267a35c

Bujalance-Moreno, P, Latorre-Román, P.Á. \& García-Pinillos, F. (2019). A systematic review on smallsided games in football players: Acute and chronic adaptations. Journal of Sports Science, 37(8), 921-949. https://doi.org/10.1080/02640414.2018.1535821

Bekris, E., Gioldasis, A. \& Gissis, I. (2014). Small-sided games and balance in soccer. International Journal in Science Research, 3(3), 1-3.

Capranica, L., Tessitore, A., Guidetti, L. \& Figure, F. (2001). Heart rate and match analysis in prepubescent soccer players. Journal of Sports Science, 19(6), 379-384. https://doi.org/10.1080/026404101300149339 
Casamichana, D. \& Castellano. J. (2010). Time-motion, heart rate, perceptual and motor behaviour demands in small-sides soccer games: Effects of pitch size. Journal of Sports Science, 28(14), 16151623. https://doi.org/10.1080/02640414.2010.521168

Casamichana, D. \& Castellano, J. (2015). The relationship between intensity indicators in small-sided soccer games. Journal in Human Kinetics, 46(1), 119-128. https://doi.org/10.1515/hukin-2015-0040

Casamichana, D., Bradley, P.S. \& Castellano, J. (2018). Influence of the varied pitch shape on soccer players physiological responses and time-motion characteristics during small-sided games. Journal in Human Kinetics, 64(1), 171-180. https://doi.org/10.1515/hukin-2017-0192

Clemente, F.M., Wong, D.P., Martins, F.M.L. \& Mendes, R.S. (2014). Acute effects of the number of players and scoring method on physiological, physical, and technical performance in small-sided soccer games. Research in Sports Medicine, 22(4), 380-397. https://doi.org/10.1080/15438627.2014.951761

Faude, O., Steffen, A., Kellmann M. \& Meyer, T. (2014). The effect of short-term interval training during the competitive season on physical fitness and signs of fatigue: A crossover trial in high-level youth football players. International Journal in Sports Physiology and Performance, 9(6), 936-944. https://doi.org/10.1123/ijspp.2013-0429

Ford, P.R., Yates, I. \& Williams, A.M. (2010). Analysis of practice activities and instructional behaviour used by youth soccer coaches during practice: Exploring the link between science and application. Journal of Sports Science, 28(5), 483-495. https://doi.org/10.1080/02640410903582750

Gaudino, P., Alberti, G. \& laia, F.M. (2014). Estimated metabolic and mechanical demands during different small-sided games in elite soccer players. Human Movement Science, 14(36), 123-133. https://doi.org/10.1016/j.humov.2014.05.006

Giménez, J.V., Liu, H., Lipińska, P., Szwarc, A., Rompa, P. \& Gómez, M.A. (2018). Physical responses of professional soccer players during 4 vs 4 small-sided games with mini-goals according to rule changes. Biology of Sport, 35(1), 75-81. https://doi.org/10.5114/biolsport.2018.70754

Gonçalves, B., Marcelino, R., Torres-Ronda, L, Torrents, C. \& Sampaio, J. (2016). Effects of emphasizing opposition and cooperation on collective movement behavior during football small-sided games. Journal of Sports Science, 34(14), 1346-1354. https://doi.org/10.1080/02640414.2016.1143111

Halouani, J., Chtourou, H., Dellal, A., Chaouachi, A. \& Chamari, K. (2017). Soccer small-sided games in young players: rule modification to induce higher physiological responses. Biology of Sport, 34(2), 163-168. https://doi.org/10.5114/biolsport.2017.64590

Hill-Haas, S.V., Coutts, A., Roswell, G. \& Dawson, B. (2008). Variability of acute physiological responses and performance profiles of youth soccer players in small-sided games. Journal of Science in Medicine and Sport, 11(5), 487-490. https://doi.org/10.1016/j.jsams.2007.07.006

Hill-Haas, S.V., Coutts, A.J., Rowsell, G.J. \& Dawson, B.T. (2009). Generic versus small-sided game training in soccer. International Journal in Sports Medicine, 30(9), 636-642. https://doi.org/10.1055/s$\underline{0029-1220730}$

Hill-Haas, S.V., Dawson, B. \& Impellizzeri, F.M. (2011). Coutts AJ. Physiology of small-sided games training in football. Sports Medicine, 41(3), 199-220. https://doi.org/10.2165/11539740-00000000000000

Hodgson, C., Akenhead, R. \& Thomas, K. (2014). Time-motion analysis of acceleration demands of 4v4 small-sided soccer games played on different pitch sizes. Human Movement Science, 33(1), 25-32. https://doi.org/10.1016/j.humov.2013.12.002

Impellizzeri, F.M., Marcora, S.M., Castagna, C., Reilly, T., Sassi, A., laia, F.M. \& Rampinini, E. (2006). Physiological and performance effects of generic versus specific aerobic training in soccer players. International Journal of Sports Medicine, 27(6), 483-492. https://doi.org/10.1055/s-2005-865839 
Köklü, Y., Alemdaroğlu, U., Cihan, H. \& Wong, D.P. (2017). Effects of bout duration on players' internal and external loads during small-sided games in young soccer players. International Journal in Sports Physiology and Performance, 12(10), 1370-1377. https://doi.org/10.1123/ijspp.2016-0584

Little, T. \& Williams, A.G. (2007). Measures of exercise intensity during soccer training drills with professional soccer players. Journal in Strength and Conditioning Research, 21(2), 367-371. https://doi.org/10.1519/00124278-200705000-00013

Mallo, J. \& Navarro, E. (2008). Physical load imposed on soccer players during small-sided training games. Journal in Sports Medicine and Physical Fitness, 48(2), 166-171.

Owen, A.L., Wong, D.P., McKenna, M. \& Dellal, A. (2011). Heart rate responses and technical comparison between small-vs-large-sided games in elite professional soccer. Journal in Strength and Conditioning Research, 25(8), 2104-2110. https://doi.org/10.1519/JSC.0b013e3181f0a8a3

Rampinini, E., Impellizzeri, F.M., Castagna, C., Abt, G., Chamari, K., Sassi, A. \& Marcora, S.M. (2007). Factors influencing physiological responses to small-sided soccer games. Journal of Sports Science, 25(6), 659-666. https://doi.org/10.1080/02640410600811858

Rebelo, A.N.C., Silva, P., Rago, V., Barreira, D. \& Krustrup, P. (2016). Differences in strength and speed demands between 4vs4 and 8vs8 small-sided football games. Journal of Sports Science, 34(24), 2246-2254. https://doi.org/10.1080/02640414.2016.1194527

Sanchez-Sanchez, J., Hernández, D., Casamichana, D., Martínez-Salazar, C., Ramirez-Campillo, R. \& Sampaio, J. (2017). Heart rate, technical performance, and session-RPE in elite youth soccer smallsided games played with wildcard players. Journal in Strength and Conditioning Research, 31(10), 2678-2685. https://doi.org/10.1519/JSC.0000000000001736

Sanchez-Sanchez, J., Ramirez-Campillo, R., Carretero, M., Martín, V., Hernández, D. \& Nakamura, F.Y. (2018). Soccer small-sided games activities vary according to the interval regime and their order of presentation within the session. Journal in Human Kinetics, 62(1), 167-175. https://doi.org/10.1515/hukin-2017-0168

Smeeton, N.J., Ward, P. \& Williams, A.M. (2004). Do pattern recognition skills transfer across sports? A preliminary analysis. Journal of Sports Science, 22(2), 205-213. https://doi.org/10.1080/02640410310001641494

\section{(9) $\odot \Theta \Theta$}

This work is licensed under a Attribution-NonCommercial-NoDerivatives 4.0 International (CC BY-NC-ND 4.0). 